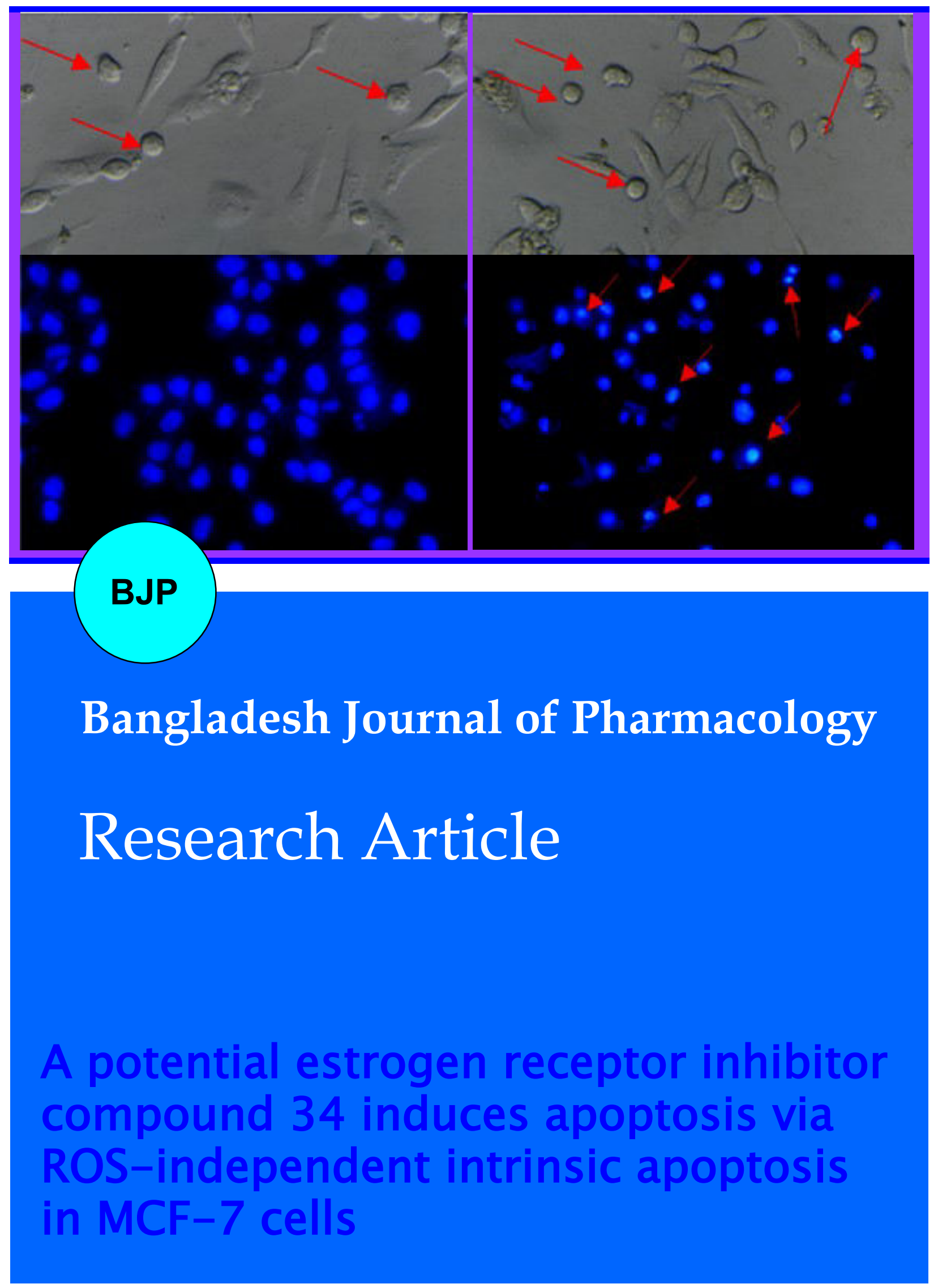




\title{
A potential estrogen receptor inhibitor compound 34 induces apoptosis via ROS-independent intrinsic apoptosis in MCF-7 cells
}

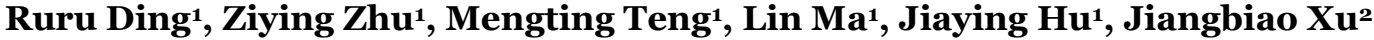 \\ and Peng Zhang1
}

${ }^{1}$ School of Life Sciences, Jiangsu Normal University, Xuzhou 221116, China; ${ }^{2}$ School of Chemistry and Chemical Engineering, Jiangsu Normal University, Xuzhou 221116, China.

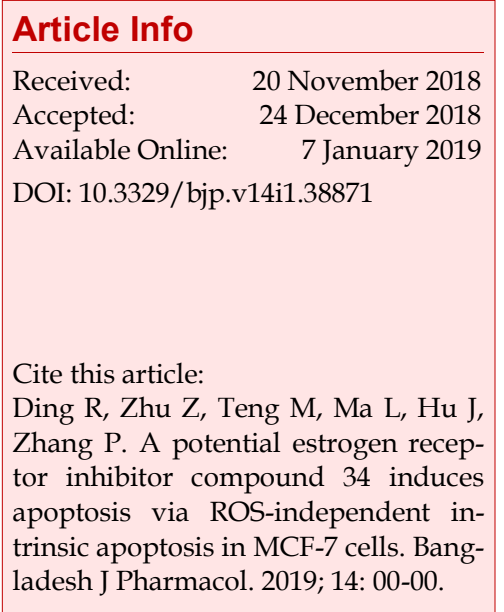

\begin{abstract}
This study aimed to investigate the anti-tumor effect of the compound 34 on MCF-7 cells in vitro and explore its mechanisms. The MTT assay results showed that the compound $\mathbf{3 4}$ selectively inhibited the estrogen receptorpositive cells proliferation. Hoechst 33342 staining showed nuclear pyknosis, nuclear debris associated with apoptotic bodies. JC-1 staining showed the loss of mitochondrial membrane potential. Although the compound increased the intracellular reactive oxygen species (ROS), the apoptosis was not prevented by pretreatment with ROS scavengers. The Western blotting showed apoptosis-related protein like cytochrome $c$, and cleaved PARP protein increased. Furthermore, docking studies exhibited that the compound could bind to ERa. In summary, compound 34 selectively inhibited the estrogen receptor positive cells proliferation and induced apoptosis in MCF-7 cells via ROS-independent intrinsic apoptosis in MCF-7 cells. It may be a potential targeted drug of estrogen receptor for therapeutic application of breast cancer.
\end{abstract}

\section{Introduction}

Breast cancer is one of the common diseases among women. The estrogen receptor is overexpressed in $70 \%$ of breast cancers. It acts as a transcription factor to influence cell differentiation, proliferation, and apoptosis (Ascenzi et al., 2006). When the estrogen receptor is activated by estrogen, it is transferred to the nucleus and binds to DNA to regulate gene expression (Helguero et al., 2005).

Breast cancer endocrine targeted therapy is to block the binding between estrogen and estrogen receptors, thereby affecting the cell signal transduction and gene transcription to inhibit tumors. Tamoxifen, as the first FDA-approved estrogen receptor modulator, significantly extends the survival of breast cancer (ER+) patients (Jordan, 1995; Jordan, 2003). However, 30-40\% of breast cancer patients develop resistance after taking 3-5 years of tamoxifen, which affects the prognosis of patients (Merenbakh-Lamin et al., 2013; Robinson et al., 2013; Toy et al., 2013). Therefore, it is particularly important to develop new estrogen receptor inhibitors to overcome the drug resistance problem (Ciruelos Gil, 2014).

In the previous study, we used MTT assay screening compounds that inhibited estrogen receptor positive cells selectively from our compound library. Fortunately, it was found a naphthoquinone derivative compound 34 (Figure 1) that showed excellent inhibition of MCF-7, Hela and HepG2 cells (estrogen receptor positive) compared to the same concentration of MDA-MB-231 (estrogen receptor negative). Nevertheless, the exact molecular mechanism by which compound 34 induces apoptosis in MCF-7 cells is still unclear. In this study, we aimed to reveal the role of both ROS and the intrinsic apoptotic pathways in the anti-cancer effect of compound $\mathbf{3 4}$ against MCF-7 cells. 


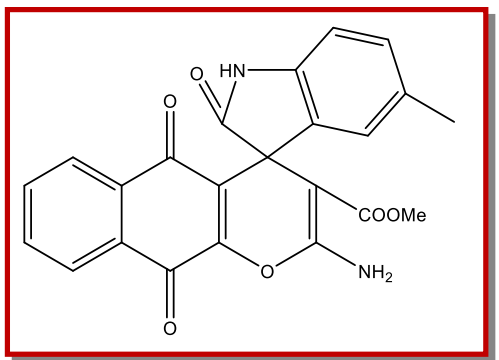

Figure 1: Structure of compound 34

\section{Materials and Methods}

\section{Tested drug}

Compound 34 was designed and synthesized by the Key Laboratory for Biotechnology on Medicinal Plants of Jiangsu Province.

\section{Cell lines}

The human cancer cell lines MCF-7, MDA-MB-231, Hela, HepG2, were purchased from the Cell Bank of Chinese Academy of Sciences (Shanghai).

\section{Reagents}

Hoechst 33342 were purchased from the Sigma Chemical Co., USA. $\beta$-actin, cytochrome $c$, Bax, Bcl-2

\section{Box 1: MTT assay}

\section{Principle}

The MTT is converted to formazan crystals within the living cells. It determines the mitochondrial activity of viable cells.

\section{Uses}

The in vitro cytotoxic effect of drug on cell lines is determined.

\section{Requirements}

Biocabinet (Class 2B); Centrifuge (benchtop); Dimethyl sulfoxide; 3-[4,5-dimethylthiazol-2-yl]-2,5-diphenyl tetrazolium bromide (MTT, Sigma Chemical Co., USA; $0.5 \mathrm{mg} / \mathrm{mL}$ ); DMEM medium (Hyclone, USA) containing $2.5 \%$ fetal bovine serum; Electronic balance; Fetal bovine serum; MCF-7 cells (Cell Bank of Chinese Academy of Sciences (Shanghai, China); Incubator; Microplate (96-well); Gas cylinder (carbon dioxide); Opti-MEM low phenol red medium (GIBCO, USA); Magnetic stirrer; Micropipettes (single channel, 0.001-1 mL, multichannel, 0.01-0.3); Molecular device microplate reader (Molecular Devices, USA); Phosphate buffer solution; Plate shaker; Syringe filter ( $0.22 \mu \mathrm{m}$ pore size, Millipore, USA)

\section{Preparation of solutions}

MTT solution: Weigh $5 \mathrm{mg}$ of MTT powder by an electronic balance and dissolve it into $10 \mathrm{~mL}$ of phosphate buffer solution. Stir the solution using a magnetic stirrer. Filter the solution by a syringe filter. The solution was stored at $-20^{\circ} \mathrm{C}$

Dissolution solution: Dimethyl sulfoxide was used as dissolution solution

\section{Procedure}

Step 1: Cells were seeded in 96 -well plates at $5 \times 10^{3}$ per well in DMEM medium containing $2.5 \%$ fetal bovine serum and caspase-3 antibodies were purchased from the Santa Cruz Biotechnology USA; HRP-labelled goat antirabbit IgG antibody and HRP-labeled goat anti-mouse IgG antibody were from the Hua'an Bio (Hangzhou, China); 1-Step ${ }^{\mathrm{TM}}$ Ultra TMB-blotting solution was from the Invitrogen (Thermo Fisher Scientific, USA).

\section{Hoechst 33342 staining}

In order to observe nuclear damage, Hoechst 33342 staining was done ( $\mathrm{Li}$ et al., 2014). The MCF-7 cells were seeded in 24 -well plates at $5 \times 10^{4}$ cells per well. The fresh medium containing indicated concentrations of compound 34 was added for 24 hours. The Hoechst 33342 staining solution was added into the wells after being washed twice by the phosphate buffer solution. The cells were incubated at $37^{\circ} \mathrm{C}$ for $20 \mathrm{~min}$. 3-5 fields per well were taken with a fluorescence microscope (Nikon, Japan) for photographing.

\section{JC-1 staining and ROS generation detection in MCF-7 cells}

To determine the intracellular changes in mitochondrial membrane potential $(\Delta \Psi \mathrm{m})$ and ROS generation, staining assays were performed (Rasul et al., 2013). The MCF-7 cells were seeded in 24-well plates at $5 \times 10^{4}$ cells per well for 12 or 24 hours. The fresh medium

Step 2: After 12 hours, cells were incubated with Opti-MEM low phenol red medium containing different concentrations of compound $\mathbf{3 4}$ for 24 or 48 hours. Compound-free wells were used as negative controls

Step 3: Ten microliters of MTT $(0.5 \mathrm{mg} / \mathrm{mL})$ was added in each well

Step 4: Shake the microplate for $5 \mathrm{~min}$ on a plate shaker by slowly increasing the shaking speed to a maximum of 900 shakes/min

Step 5: Incubate the microplate for another 4 hours at $37^{\circ} \mathrm{C}$ in a $\mathrm{CO}_{2}$ incubator

Step 6: One hundred and fifty microliters of dimethyl sulfoxide was added to dissolve the formazan

Step 7: Finally, the absorbance values measured at optical density of 560 and $670 \mathrm{~nm}$ by a molecular device microplate reader

Inhibition rate $(\%)=1-($ control - compound treated $) /$ control $\times 100 \%$

\section{Explanation}

Syringe filter was used to sterilize the MTT solution. Dimethyl sulfoxide was used to dissolve the formazan crystals within the cell. Some researchers use isopropanol, methanol, ethanol instead of dimethyl sulfoxide.

\section{Precaution}

MTT is toxic and harmful. It is light sensitive, hence protect it from light. The unused MTT solution may be frozen for reuse.

\section{References}

Kou et al., 2017; Bahuguna et al., 2017 
containing indicated concentrations of compound $\mathbf{3 4}$ was added for 24 hours. Then the cells were washed twice by phosphate buffer solution and then added JC-1 staining solution (KeyGen Biotech. Inc., China) or DCFH-DA kit (Sigma Chemical Co, USA) for $20 \mathrm{~min}$ at $37^{\circ} \mathrm{C}$. Finally, 3-5 fields per well were captured with a fluorescence microscope (Nikon, Japan). Image J software version 1.46r (National Institutes of Health, USA) was used to analyze the fluorescence quantitative.

\section{Wound healing assay}

In order to investigate the effect of compound 34 on the migration of MCF-7 cells, wound healing assay was performed as described elsewhere (Si et al., 2018). The MCF-7 cells were seeded in 24-well plates at $5 \times 10^{4}$ cells per well. After 24 hours, the cells were incubated in low-phenol red medium for 24 hours. When the cells reach $90 \%$ confluence, scrape the cells with a sterile pipette tip. Then the cells of different concentrations of compound $\mathbf{3 4}$ were treated and photographed under a microscope (Nikon, Japan). The healing areas were analyzed using Image J software version 1.46r (National Institutes of Health, USA).

\section{Western blotting detection of cellular protein expre- ssion}

To explore the mechanism of the apoptotic effect of compound 34, Western blotting was performed for detecting apoptotic related proteins as previously described (Rasul et al., 2012a). The MCF-7 cells were seeded in $60 \mathrm{~mm}$ dishes and cultured for 24 hours. The compound 34 was added at the concentration of $6 \mu \mathrm{g} /$ $\mathrm{mL}$. After 12 hours, the cells were collected and lysed using RIPA. The BCA method was used to detect the protein concentration. SDS-PAGE was used to separate proteins and then transfer the protein to the NC membrane. After blocked by $5 \%$ non-fat milk for 1 hour, the membrane was incubated with indicated primary antibodies overnight at $4^{\circ} \mathrm{C}$. After then the NC membrane was washed with PBST three times (5 min each time). The membrane was incubated in HRPlabeled secondary antibodies for 2 hours at room temperature. After washing with PBST three times (10 min each time), the NC membrane was visualized by using TMB coloring solution for $5 \mathrm{~min}$. The photos were taken by Image Lab 5.0 (Bio-Rad Laboratories, USA) and the density values were calculated by Image J (National Institutes of Health, USA).

\section{Molecular docking}

The estrogen receptor a structure (PDB code: 3ERT) was downloaded from the Protein Data Bank, and the compound structure was drawn using ChemDraw. The structure was uploaded to the online docking site (http://systemsdock.unit.oist.jp/iddp/home/index/), and we performed the molecular docking according to the protocol operation of the website (Hsin et al., 2016). Discovery Studio 4.5 software was used to visualize the docking result.

\section{Statistical analysis}

All experiments were performed in triplicates or repeated at least two times unless otherwise stated. The IBM SPSS statistics 23 (SPSS Inc. USA) was used for statistical analysis. The experimental data were expressed as mean $\pm S D$ and used one-way analysis of variance or the Student's t-test. $\mathrm{p}<0.05$ was considered statistically significant.

\section{Results}

\section{Estrogen receptor positive cells}

The line graph drawn from the MTT results (Figure 2)

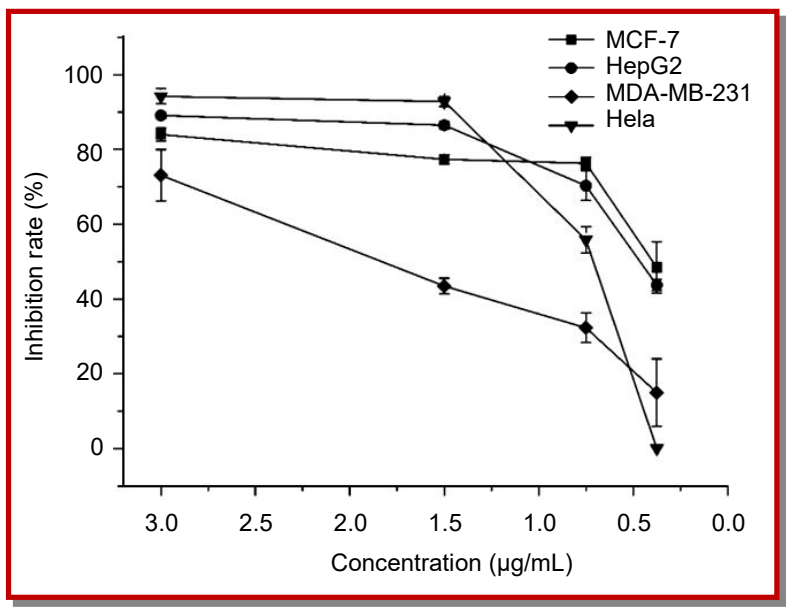

Figure 2: The inhibition rate of cell lines after treatment for 24 hours

Cells were seeded in 96 well plates and incubated with indicated concentration of compound 34. Cell viability was determined using MTT cell proliferation assay kits

showed that compound $\mathbf{3 4}$ was more effective in the estrogen receptor positive cell line MCF-7, HepG2 and Hela cells than the MDA-MB-231 cells. At the concentration of $0.75 \mu \mathrm{g} / \mathrm{mL}$, the inhibitory rate of estrogen receptor-positive cells could still up 50\%, while the inhibition rate of MDA-MB-231 cells was only $30 \%$. The $\mathrm{IC}_{50}$ values in Table I also demonstrated that the compound $\mathbf{3 4}$ was more sensitive to estrogen receptor cells and in a time-dependent manner.

\section{Apoptosis}

It could be seen from the photograph of cells in Figure 3A that compared with control, the MCF-7 cells treated with compound 34 begun to shrink and round, the volume became smaller, which was a clear feature of apoptosis. However, the difference between the control and treatment groups in MDA-MB-231 cells was not significant, and the number of apoptotic cells was smaller than the MCF-7 cells. After staining with Hoechst 33342, under a fluorescence microscope (3B), 


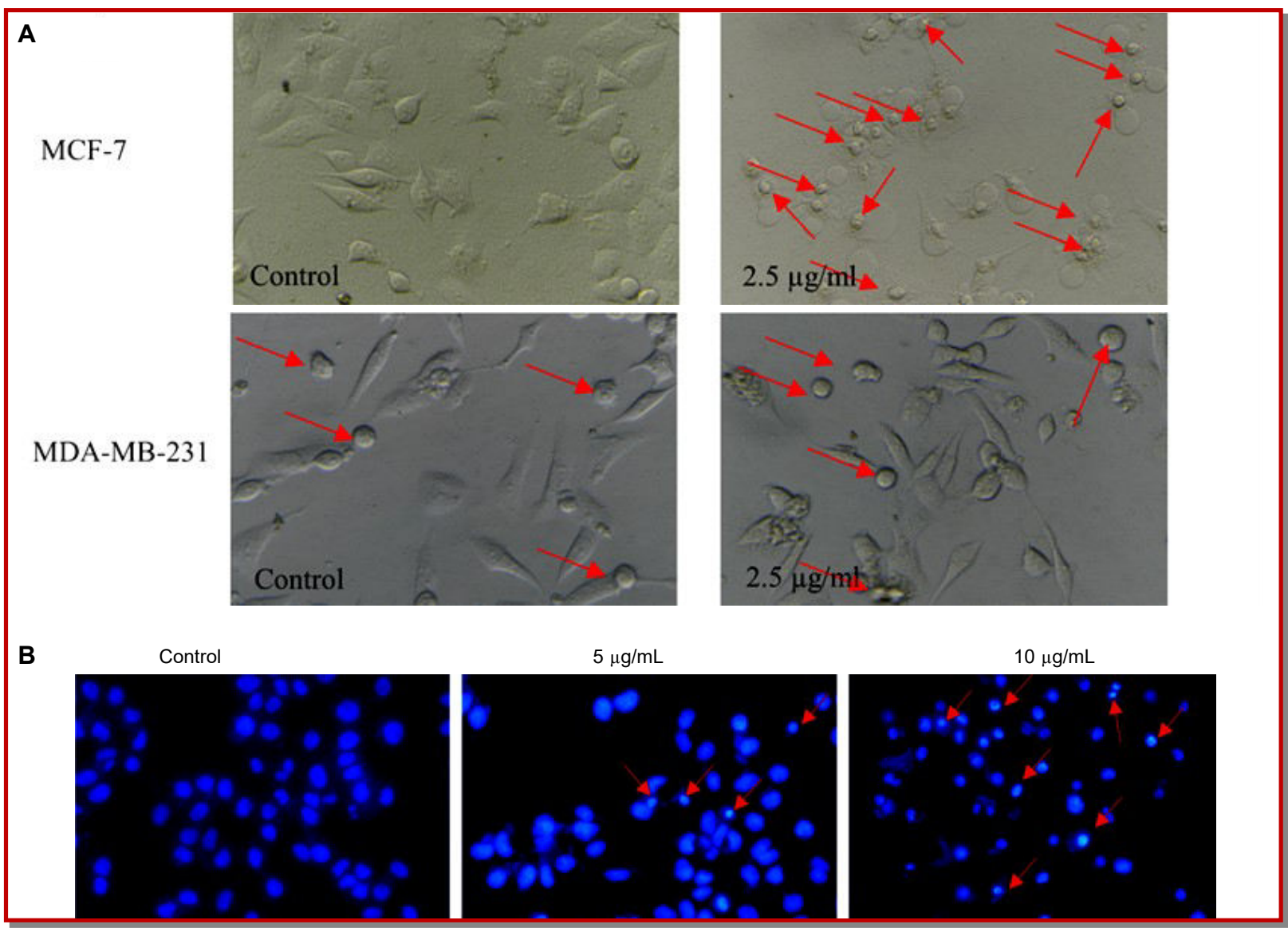

Figure 3: Effect of compound 34 on the morphological changes of two human breast cell lines

MCF-7 and MDA-MB-231 cells were treated with indicated concentrations of compound 34 for 24 hours and captured by a fluorescence microscope

\begin{tabular}{|c|c|c|}
\hline \multicolumn{3}{|c|}{ Table I } \\
\hline \multicolumn{3}{|c|}{$\mathrm{IC}_{50}$ values of cell lines } \\
\hline Cell line & $\begin{array}{c}\mathrm{IC}_{50}(\mu \mathrm{g} / \mathrm{mL}) \\
24 \text { hours }\end{array}$ & $\begin{array}{c}\mathrm{IC}_{50}(\mu \mathrm{g} / \mathrm{mL}) \\
48 \text { hours }\end{array}$ \\
\hline MCF-7 (ER+) & 0.5 & 0.2 \\
\hline Hela (ER+) & 1.0 & 0.9 \\
\hline HepG2 (ER+) & 0.4 & 0.3 \\
\hline MDA-MA-231(ER-) & $>1.5$ & $>2$ \\
\hline $\begin{array}{l}\text { ER+ : Represents estro } \\
\text { gen receptor negative }\end{array}$ & ptor positive. E & Represents estro- \\
\hline
\end{tabular}

the nucleus of normal MCF-7 cells was normal blue, but the nucleus of the compound-treated cells was densely stained, and the color was somewhat whitish. These results indicated that the compound 34 could induce apoptosis in MCF-7 cells.

\section{Mitochondrial membrane potential and generated ROS}

The mitochondrial membrane potential of normal cells was high, and JC-1 accumulated in the mitochondrial matrix to form the polymer, showing red fluorescence. When the cell apoptosis occurred, the membrane potential decreased, JC-1 could not accumulate in the mitochondrial matrix, indicating green fluorescence. As Figure 4A shows, the control group was red fluorescence, but with the increase of the concentration of compound 34, the green fluorescence was enhanced. When the concentration of compound 34 was $10 \mu \mathrm{g} /$ $\mathrm{mL}$, the field of view was all of the green, indicating that the mitochondrial membrane potential showed a significantly decreasing trend. The decrease in mitochondrial membrane potential was more evident from the fluorescence quantitative results in Figure 4B.

As shown in Figure 4C, the green fluorescence was more clearly in the treated group. This phenomenon suggested that compound $\mathbf{3 4}$ could generate ROS and change the mitochondrial membrane potential of MCF7 cells.

\section{ROS-independent intrinsic apoptosis}

To explore whether ROS was involved in compound 34induced apoptosis in MCF-7 cells, we first used MTT assay to assess the effects of pretreatment with $5 \mathrm{mM}$ NAC (a free radical scavenger). We found that this ROS scavenger did not prevent compound 34-induced cytotoxicity (Figure 5B). To further investigate the effect 


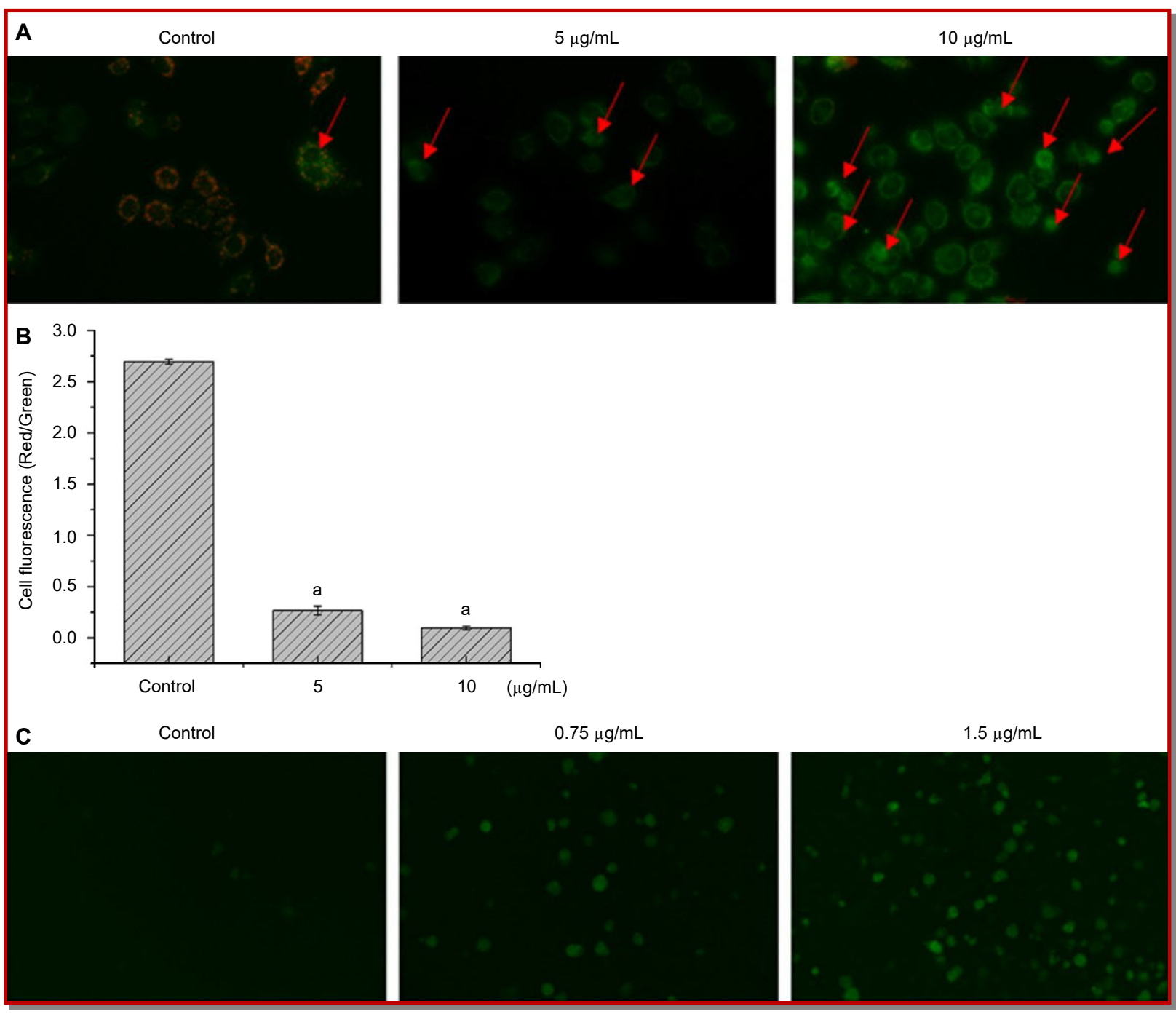

Figure 4: Effect of compound 34 on mitochondrial membrane potential $(\Delta \Psi \mathrm{m})$ levels and ROS generation in MCF-7

(A) MCF-7 cells were treated with different concentrations of compound 34 for 24 hours and the mitochondrial membrane potential was detected by JC-1 staining; (B) The fluorescence quantitative results of JC-1 staining, results are expressed as the means \pm SD; ap $<0.01$ compared with control group; (C) MCF-7 cells were incubated with various concentrations of compound 34 for 12 hours and a fluorescence microscope captured the ROS production using DCFH-DA kit

of ROS on compound 34-induced cell morphological alterations, the cells were visualized with a fluorescence microscope. As shown in Figure 5A, pretreatment with NAC could also decrease the number of cells and showed a rounded morphology in MCF-7 cells. We thus concluded that compound 34 induced ROSindependent cytotoxicity in MCF-7 cells.

The treatment of MCF-7 cells with compound 34 for 12 hours induced a decline in procaspase- 3 and the biomarker of intrinsic pathway protein cytochrome $c$ increased compared to control at the same time (Figure $5 \mathrm{C})$. An essential feature of the Bcl-2 family of proteins is that family members can form dimers that regulate cell apoptosis. The experiment found that the expression level of pro-apoptotic protein Bax significantly increased, but the expression of anti-apoptotic protein BcL-2 did not change obviously. Besides, cleaved PARP increased compared with control.

Taken together, these results suggested that compound 34 induced ROS-independent intrinsic apoptosis in MCF-7 cells.

\section{Effect on the migration of MCF-7 cells}

From the pictures (Figure 6), it could be seen that the scratched area of the drug treatment group was larger than the control group regardless of 6 or 24 hours. Quantitative analysis by Image $\mathrm{J}$ showed that the migration rate was 20.5 and $55.9 \%$ in the control group while the drug treatment group was $4.5 \%(\mathrm{p}<0.01)$ and $23.7 \%(p<0.05)$ at 6 and 24 hours respectively. These data suggested that compound 34 inhibited the migration of MCF-7 cells. 


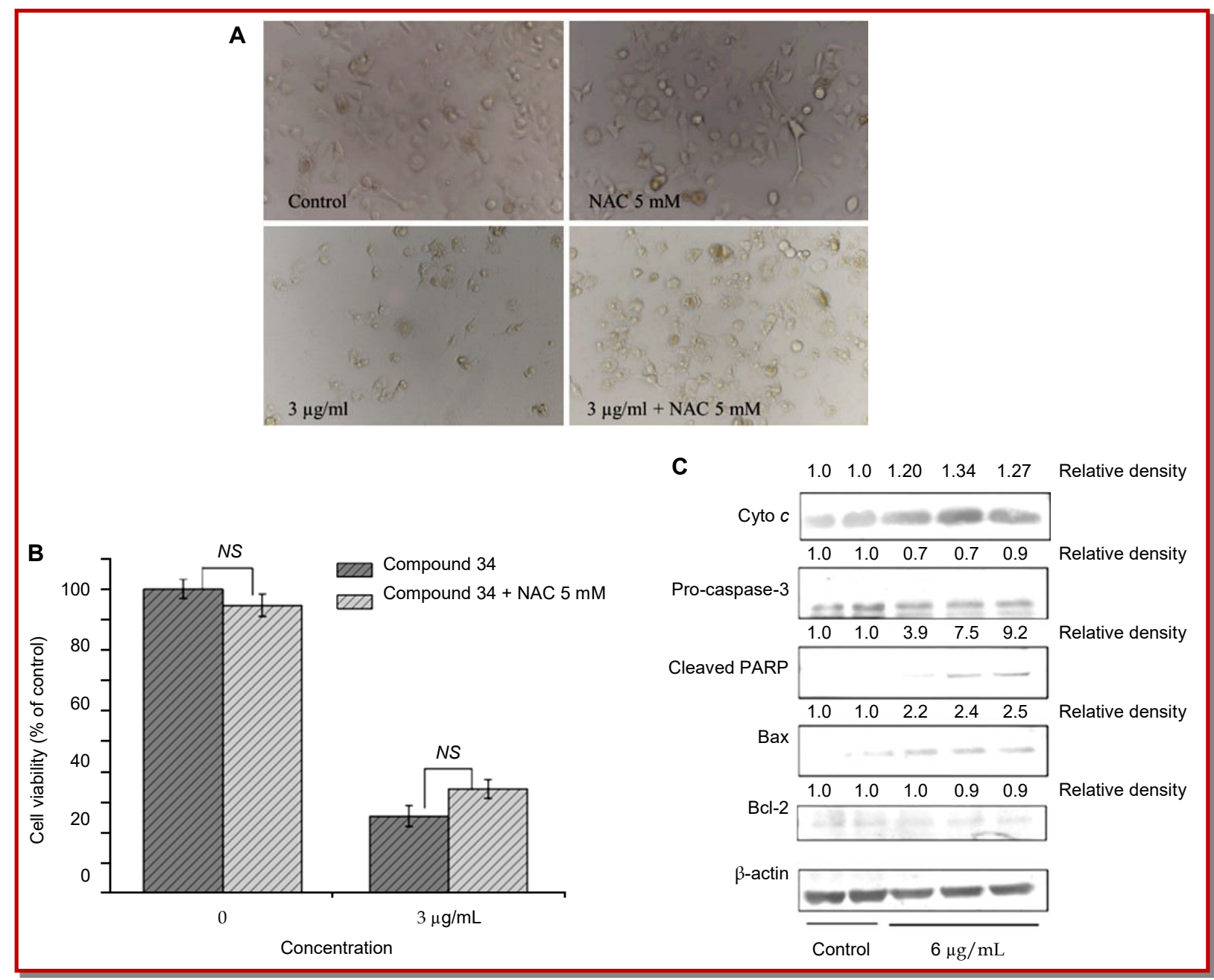

Figure 5: Compound 34 induces ROS-independent intrinsic apoptosis

(A) and (B) Cells were treated with $3 \mu \mathrm{g} / \mathrm{mL}$ compound 34 for 12 hours and then pre-incubated with 5 mM NAC for 4 hours before MTT assay or morphological observation. (C) Cells were treated with indicated concentrations of compound 34 for 12 hours, followed by Western blot analysis with indicated antibodies. $\beta$-actin was used as a loading control. NS means no statistical significance, $p>0.05$

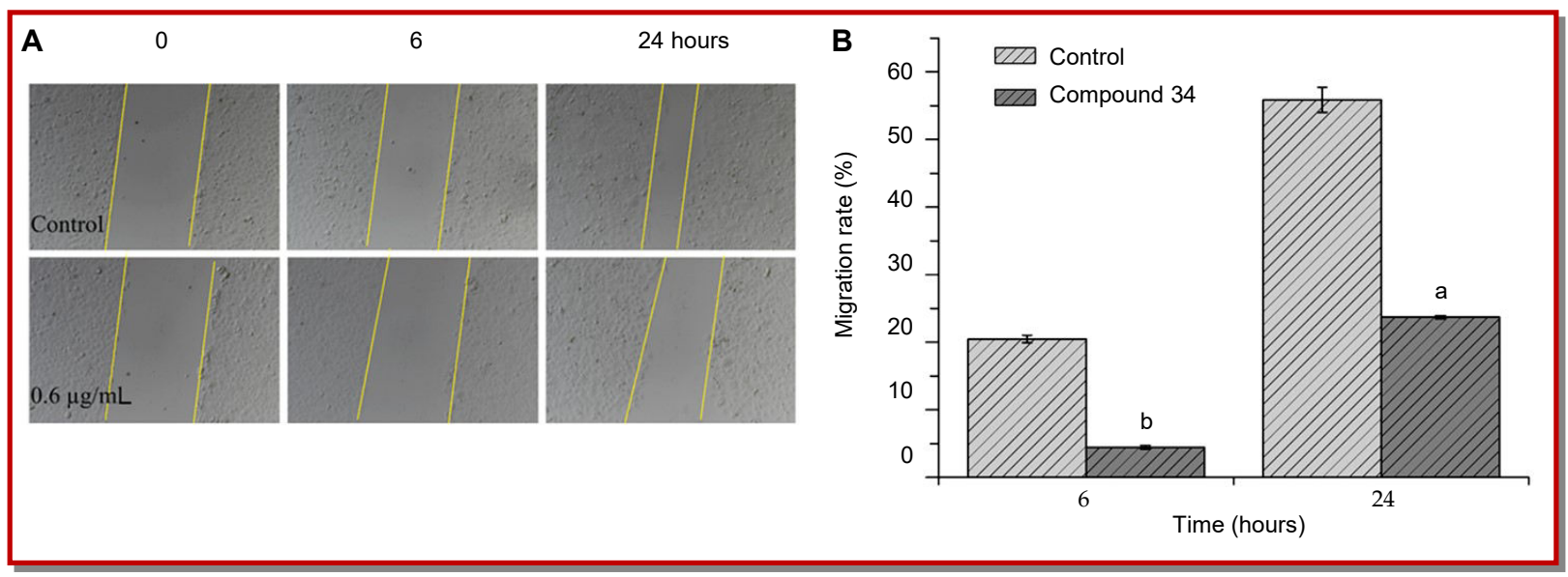

Figure 6: Compound 34 decreased MCF-7 cells migration

(A) Images of the wound healing ability of MCF-7 cells treated with compound 34 at $0.6 \mu \mathrm{g} / \mathrm{mL}$ for 6 and 24 hours. (B) Analysis of the wound closure rate of MCF-7 cells by quantitation. Data are presented as the means $\pm S D$, a $p<0.05,{ }^{b} p<0.01$ as compared with control group 


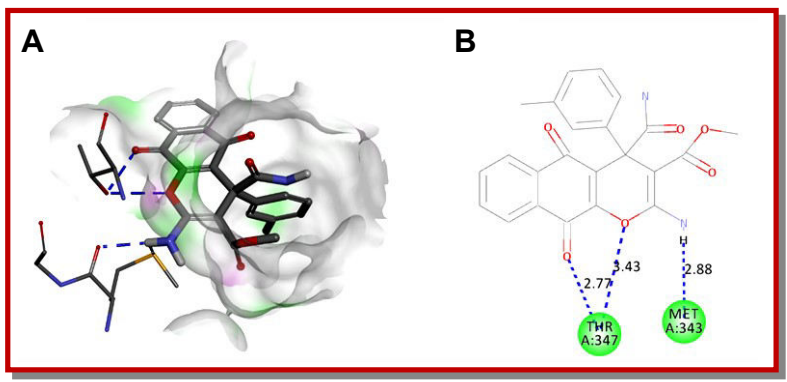

Figure 7: The binding mode between the active conformation of compound 34 and the estrogen receptor $a$

(A) The receptor surface model with compound 34. (B) The 2D diagram of interactions between compound 34 and the estrogen receptor $\alpha$. The H-bond (blue arrows) is displayed as dashed arrows

\begin{tabular}{|lccc|}
\hline \multicolumn{3}{|c|}{ Table II } \\
\hline \multicolumn{3}{|c|}{ Docking score of compound 34 } \\
\hline Protein & PDB ID & $\begin{array}{c}\text { Test com- } \\
\text { pound }\end{array}$ & $\begin{array}{c}\text { Docking score } \\
\text { (pKd/pKi) }\end{array}$ \\
\hline $\begin{array}{l}\text { ESR1 (ESR1) } \\
\text { ESR1 (ESR1) }\end{array}$ & 3ERT & 34 & 4.7 \\
$\begin{array}{l}\text { Explanation: The score reported by docking approach is a negative } \\
\text { logarithm of experimental dissociation/inhibition constant value } \\
\text { (pKd/pKi) usually ranging from 0 to 10 (i.e. from weak to strong } \\
\text { binding), allowing a straightforward indication of binding strength }\end{array}$ \\
\hline
\end{tabular}

\section{Molecular modeling}

Molecular docking studies were performed to explore the potential binding ability between compound $\mathbf{3 4}$ and ERa. As is shown in Figure 7A, the compound 34 was located into the binding pocket of ERa, and the side chain stretches toward the edge of the pocket. Moreover, compound $\mathbf{3 4}$ formed two hydrogen bonds with Thr 347(A) and Met 343(A) respectively (7B). Furthermore, the docking score of compound 34 (Table II) was 4.7, higher than the docking score of tamoxifen, indicating a good affinity for binding to ERa.

\section{Discussion}

Almost $70 \%$ of breast cancer patients are estrogen receptor alpha (ERa) positive and estrogen-dependent. Estrogen receptors play a crucial role in the development and progression of breast cancer which function as a transcription factor to influence cell differentiation, proliferation, and apoptosis (Anderson et al., 2002). Endocrine therapy is a treatment of breast cancer by preventing estrogen from binding estrogen receptors. Tamoxifen is the first generation of estrogen receptor modulators in clinical practice for the treatment of metastatic breast cancer and has achieved great therapeutic effects (Renoir et al., 2013). The estrogen receptor has become a promising target for synthesizing low-toxic and highly effective estrogen receptor inhibitors (Ariazi and Jordan, 2006).

Naphthoquinones are a kind of common natural compounds, which have bactericidal, anti-oxidant and antiviral effects (Zhivetyeva et al., 2016; Novais et al., 2018). Some studies have shown that naphthoquinone derivatives have anti-tumor and apoptosis-inducing effects $(\mathrm{Li}$ et al., 2017; Liu et al., 2018). In this study, we found a compound which can selectively inhibit MCF-7 cells (estrogen receptor positive) but has lower cytotoxicity against MDA-MB-231(estrogen receptor negative). Also, we found that MCF-7 cells were more toxic to compound 34 when estrogen in MCF-7 cells was deprived for 24 hours (supplement). On the other hand, phenol red in culture media significantly attenuated the inhibition of MCF-7 cells (supplement). The reason may be that phenol red can simulate the effects of estrogen (Berthois et al., 1986; Welshons and Jordan, 1987) and result in the competitive binding with estrogen receptors between compound $\mathbf{3 4}$ and estrogens. Previous studies have demonstrated that raloxifene and tamoxifen could be metabolized by both rat or human liver microsomes to electrophilic diquinone methide and oquinones and the classical electrophilic quinone methide might contribute to the potential toxicity of raloxifene and tamoxifen (Yu et al., 2004; Liu et al., 2005; Dowers et al., 2006). From the literature reports and our MTT experimental data, we hypothesized compound 34 was likely to be an estrogen receptor inhibitor. We continued to explore its mechanism of inhibiting MCF-7. Hoechst 33342 is a common dyeing solution for detecting apoptosis. Fluorescent photographs showed that the MCF-7 cells treated with compound 34 were densely stained and the cells of control were natural blue, which revealed that compound 34 could induce apoptosis in MCF-7 cells. Next, we detected the changes of mitochondrial membrane potential by JC-1 staining, because the decrease in mitochondrial membrane potential is a sign of early cell apoptosis. The results showed that the cells in the control group were red, and gradually turned green as the compound concentration increased, indicating that the mitochondrial membrane potential was decreasing and was dose-dependent. It has been reported in the literature that quinones are highly redox active molecules which can redox cycle with their semiquinone radical anions leading to the formation of reactive oxygen species (ROS) (Bolton and Dunlap, 2017) and ROS accumulation leads to a membrane potential decrease in cellular mitochondria and activation of intrinsic apoptotic pathways (Skulachev, 2006; Yee et al., 2014). Therefore, we performed intracellular ROS assay and found that ROS was significantly accumulated in MCF-7 cells treated with compound 34 compared to the control. However, NAC did not reverse the cytotoxicity against MCF-7 cells. At the same time, Western blotting showed that the intrinsic pathway marker protein of cytochrome $c$ was increased and the 
expression level of procaspase-3 was down-regulated. Computer simulation improves the efficiency of drug development (Zhong and MacKerell, 2007), we conducted molecular target docking through the online molecular docking network. The results showed that the compound could dock with the estrogen receptor and the docking score was 4.7, better affinity than tamoxifen. Metastasis is a multi-step process that involves the movement and invasion of cancer cells, which is a key problem for cancer treatment (Deryugina and Quigley, 2006). Therefore, inhibition of metastasis is essential for effective cancer treatment. Scratch test results showed that compound 34 could inhibit cell migration, it may also be a promising migration inhibitor.

We propose the signaling pathway of compound 34induced apoptosis in MCF-7 cells as shown in Figure 8.

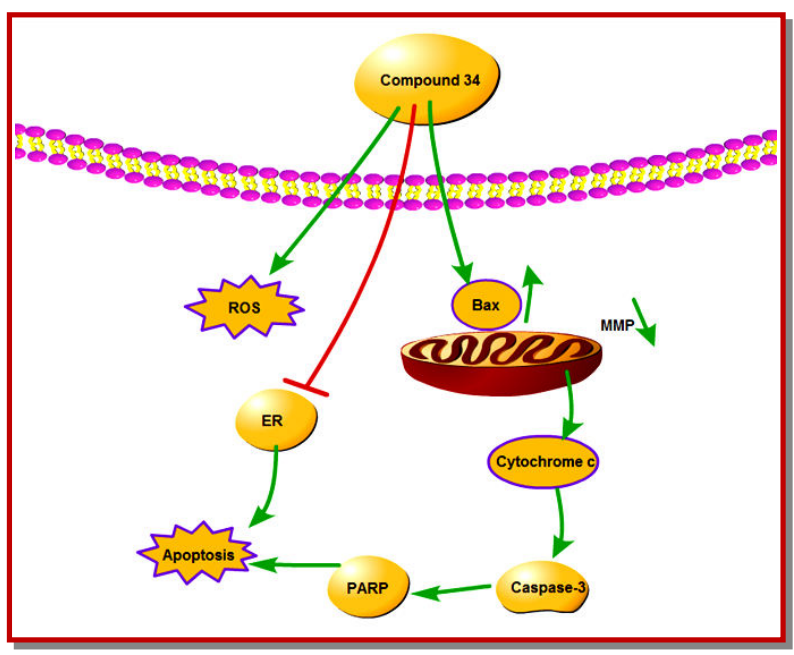

Figure 8: The possible signaling pathway for compound 34induced apoptosis in MCF-7 cells

Compound 34 can produce ROS and reduce mitochondrial membrane potential, release cytochrome $c$ from mitochondrial, activate caspase-3, and finally lead cells to death. In addition, compound 34 can also trigger apoptosis by interacting with ERa

\section{Conclusion}

A new naphthoquinone derivative (compound 34) had cytotoxic activity in human cancer cell lines, including human breast adenocarcinoma cell lines and hepatocellular liver carcinoma. Furthermore, this is the first time we demonstrated that compound 34 can induce MCF-7 cell apoptosis via ROS-independent intrinsic apoptosis pathway and interacting with ERa.

\section{Acknowledgement}

Thanks Prof. Hui Wu for designing and synthesizing compound 34. The study was supported by Postgraduate Research and Practice Innovation Program of Jiangsu Province (No. KYCX17_1615) and (No. KYCX18_2131), Innovative Entrepreneurship Training Program for College students in
Jiangsu Province (201810320150X).

\section{References}

Anderson WF, Chatterjee N, Ershler WB, Brawley OW. Estrogen receptor breast cancer phenotypes in the surveillance, epidemiology, and end results database. Breast Cancer Res Tr. 2002; 76: 27-36.

Ariazi EA, Jordan VC. Estrogen receptors as therapeutic targets in breast cancer. Curr Top Med Chem. 2006; 6: 181-202.

Ascenzi P, Bocedi A, Marino M. Structure-function relationship of estrogen receptor $\alpha$ and $\beta$ : Impact on human health. Mol Aspects Med. 2006; 27: 299-402.

Bahuguna A, Khan I, Bajpai V, Kang S. MTT assay to evaluate the cytotoxic potential of a drug. Bangladesh J Pharmacol. 2017; 12: 115-18.

Berthois Y, Katzenellenbogen JA, Katzenellenbogen BS. Phenol red in tissue culture media is a weak estrogen: Implications concerning the study of estrogen-responsive cells in culture. P Natl Acad Sci USA. 1986; 83: 2496-500.

Bolton JL, Dunlap T. Formation and biological targets of quinones: Cytotoxic versus cytoprotective effects. Chem Res Toxicol. 2017; 30: 13-37.

Ciruelos Gil EM. Targeting the PI3K/AKT/mTOR pathway in estrogen receptor-positive breast cancer. Cancer Treat Rev. 2014; 40: 862-71.

Deryugina EI, Quigley JP. Matrix metalloproteinases and tumor metastasis. Cancer Metast Rev. 2006; 25: 9-34.

Dowers TS, Qin ZH, Thatcher GRJ, Bolton JL. Bioactivation of Selective Estrogen Receptor Modulators (SERMs). Chem Res Toxicol. 2006; 19: 1125-37.

Helguero LA, Faulds MH, Gustafsson JA, Haldosen LA. Estrogen receptors alfa (ERalpha) and beta (ERbeta) differentially regulate proliferation and apoptosis of the normal murine mammary epithelial cell line HC11. Oncogene 2005; 24: 6605-16.

Hsin KY, Matsuoka Y, Asai Y, Kamiyoshi K, Watanabe T, Kawaoka Y, Kitano H. systemsDock: A web server for network pharmacology-based prediction and analysis. Nucleic Acids Res. 2016; 44: W507-13.

Jordan VC. Third annual William L. McGuire Memorial Lecture. "Studies on the estrogen receptor in breast cancer"-20 years as a target for the treatment and prevention of cancer. Breast Cancer Res Tr. 1995; 36: 267-85.

Jordan VC. Tamoxifen: A most unlikely pioneering medicine. Nat Rev Drug Discov. 2003; 2: 205-13.

Kou N, Cho H, Kim HE, Sun Q, Ahn K, Ji H, Choi H, Kim O. Anti-cancer effect of Atractylodes macrocephala extract by double induction of apoptotic and autophagic cell death in head and neck cancer cells. Bangladesh J Pharmacol. 2017; 12: $140-146$.

Li K, Wang B, Zheng L, Yang K, Li Y, Hu M, He D. Target ROS to induce apoptosis and cell cycle arrest by 5,7-dimethoxy1,4-naphthoquinone derivative. Bioorg Med Chem Lett. 2017; 28: 273-77. 
Li Q, Zhao XL, Sun J, Jiang SG, Gong XF. Anti-proliferative and apoptosis-inducing activities of juglone in LS-174T cells. Bangladesh J Pharmacol. 2013; 8: 65-72.

Liu C, Shen GN, Luo YH, Piao XJ, Jiang XY, Meng LQ, Wang Y, Zhang Y, Wang JR, Wang H, Xu WT, Li JQ, Liu Y, Wu YQ, Sun HN, Han YH, Jin MH, Cui YD, Fang NZ, Jin CH. Novel 1,4-naphthoquinone derivatives induce apoptosis via ROSmediated p38/MAPK, Akt and STAT3 signaling in human hepatoma Hep3B cells. Int J Biochem Cell Biol. 2018; 96: 9-19.

Liu J, Liu H, Breemen RBV, Thatcher GRJ, Bolton JL. Bioactivation of the selective estrogen receptor modulator acolbifene to quinone methides. Chem Res Toxicol. 2005; 18: 174-82.

Merenbakh-Lamin K, Ben-Baruch N, Yeheskel A, Dvir A, Soussan-Gutman L, Jeselsohn R, Yelensky R, Brown M, Miller VA, Sarid D, Rizel S, Klein B, Rubinek T, Wolf I. D538G mutation in estrogen receptor-a: A novel mechanism for acquired endocrine resistance in breast cancer. Cancer Res. 2013; 73: 6856-64.

Novais JS, Moreira CS, Silva ACJA, Loureiro RS, Figueiredo AMS, Ferreira VF, Castro HC, da Rocha DR. Antibacterial naphthoquinone derivatives targeting resistant strain Gramnegative bacteria in biofilms. Microb Pathogenesis. 2018; 118: 105-14.

Rasul A, Bao R, Malhi M, Zhao B, Tsuji I, Li J, Li X. Induction of apoptosis by costunolide in bladder cancer cells is mediated through ROS generation and mitochondrial dysfunction. Molecules 2013; 18: 1418-33.

Rasul A, Ding C, Li X, Khan M, Yi F, Ali M, Ma T. Dracorhodin perchlorate inhibits PI3K/Akt and NF-kappaB activation, up -regulates the expression of p53, and enhances apoptosis. Apoptosis 2012a; 17: 1104-19.

Renoir JM, Marsaud V, Lazennec G. Estrogen receptor signaling as a target for novel breast cancer therapeutics. Biochem Pharmacol. 2013; 85: 449-65.

Robinson DR, Wu YM, Vats P, Su F, Lonigro RJ, Cao X,
Kalyana-Sundaram S, Wang R, Ning Y, Hodges L, Gursky A, Siddiqui J, Tomlins SA, Roychowdhury S, Pienta KJ, Kim SY, Roberts JS, Rae JM, Poznak CHV, Hayes DF, Chugh R, Kunju LP, Talpaz M, Schott AF, Chinnaiyan AM. Activating ESR1 mutations in hormone-resistant metastatic breast cancer. Nat Genet. 2013; 45: 1446.

Si L, Yan X, Hao W, Ma X, Ren H, Ren B, Li D, Dong Z, Zheng $\mathrm{Q}$. Licochalcone $\mathrm{D}$ induces apoptosis and inhibits migration and invasion in human melanoma A375 cells. Oncol Rep. 2018; 39: 2160-70

Skulachev VP. Bioenergetic aspects of apoptosis, necrosis and mitoptosis. Apoptosis 2006; 11: 473-85.

Toy W, Shen Y, Won H, Green B, Sakr RA, Will M, Li Z, Gala K, Fanning S, King TA, Hudis C, Chen D, Taran T, Hortobagyi G, Greene G, Berger M, Baselga J, Chandarlapaty S. ESR1 ligand-binding domain mutations in hormoneresistant breast cancer. Nat Genet. 2013; 45: 1439.

Welshons WV, Jordan VC. Adaptation of estrogen-dependent MCF-7 cells to low estrogen (phenol red-free) culture. Eur J Cancer Clin Oncol. 1987; 23: 1935-39.

Yee C, Yang W, Hekimi S. The intrinsic apoptosis pathway mediates the pro-longevity response to mitochondrial ROS in C. elegans. Cell. 2014; 157: 897-909.

Yu L, Liu H, Li W, Zhang F, Luckie C, van Breemen RB, Thatcher GRJ, Bolton JL. Oxidation of raloxifene to quinoids: Potential toxic pathways via a diquinone methide and oquinones. Chem Res Toxicol. 2004; 17: 879-88.

Zhivetyeva SI, Zakharova OD, Ovchinnikova LP, Baev DS, Bagryanskaya IY, Shteingarts VD, Tolstikova TG, Nevinsky GA, Tretyakov EV. Phosphonium betaines derived from hexafluoro-1,4-naphthoquinone: Synthesis and cytotoxic and anti-oxidant activities. J Fluorine Chem. 2016; 192: 68-77.

Zhong S, Mackerell AD. Binding response: A descriptor for selecting ligand binding site on protein surfaces. J Chem Inf Model. 2007; 47: 2303-15.

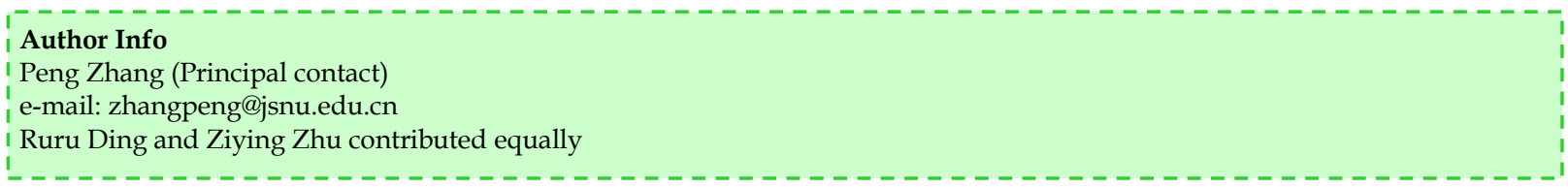

